\title{
EXPERIÊNCIAS PEDAGÓGICAS PARA ALÉM DO CAPITAL: ANÁLISE DO LIVRO "FUNDAMENTOS DA ESCOLA DO TRABALHO" DE PISTRAK ${ }^{1}$
}

\author{
EXPERIENCIAS PEDAGÓGICAS PARA MÁS DEL CAPITAL: ANÁLISIS DEL LIBRO \\ "FUNDAMENTOS DE LA ESCUELA DEL TRABAJO" DE PISTRAK
}

\section{PEDAGOGICAL EXPERIENCES BEYOND THE CAPITAL: ANALYSIS OF THE BOOK "FOUNDATIONS OF THE SCHOOL OF LABOR" OF PISTRAK \\ DOI: http://dx.doi.org/10.9771/gmed.v11i1.32215}

Israel Ramos Moreira ${ }^{2}$

O livro Fundamentos da Escola do Trabalho foi escrito em 1924, sete anos após a Revolução Russa (1917) e dois anos após a formação da União das Repúblicas Socialistas Soviéticas (1922). Assim, a proposta pedagógica apresentada por Pistrak está relacionada com o período de formação de uma cultura socialista na União Soviética. Ela pretendia formar sujeitos que seriam os construtores da recém-criada sociedade socialista e nos traz princípios e valores pautados na coletividade e na auto-organização.

A obra se inicia com uma Apresentação escrita no ano 2000 por Roseli Salete Caldart (assessora pedagógica do Instituto Técnico de Capacitação e Pesquisa da Reforma Agrária). Nela, Roseli afirma que quase não existem registros biográficos de Pistrak, mas sabe-se que suas reflexões pedagógicas influenciaram muito a educação da União Soviética no final da década de 1920 e, posteriormente, com o stalinismo, a sua obra deixou de ser divulgada.

A Apresentação nos alerta que a obra de Pistrak deve ser lida como um registro do período de construção de uma pedagogia social na União Soviética, mas cita alguns temas tratados na obra que, na opinião da autora, servem para dialogar com a prática educativa atual: 1. Pensar e fazer uma escola que seja educadora do povo; 2. Educação é mais do que ensino; 3. A vida escolar deve estar centrada na atividade produtiva; 4. A escola precisa vincular-se ao movimento social e ao mundo do trabalho; 5 . A autoorganização dos educandos como base do processo pedagógico da escola; 6. Pensar um jeito de desenvolver o ensino que seja coerente como o método dialético de interpretação da realidade; 7. Sem teoria pedagógica revolucionária não há prática pedagógica revolucionária.

Pistrak explica, no prefácio da obra, que o livro é resultado do seu trabalho prático na Escola Lepechinsky, incluindo experiências realizadas em reuniões ou cursos para professores. O autor diz que “ (...) o livro não é um manual puramente prático, mas, antes de tudo, a expressão da doutrina de pedagogia social que se desenvolveu e provou sua validade através do trabalho prático e dos problemas que ele colocou em cada momento para a Escola." (p. 15) 
O tema central do livro é educação e trabalho, a obra conta com 192 páginas e está dividida em cinco seções com as seguintes temáticas: Teoria e prática; $A$ escola do trabalho no periodo de transição; $O$ trabalho na escola; $O$ ensino; $A$ auto-organizaçãa dos estudantes. Embora haja esta divisão, os temas estão estreitamente vinculados e vão sendo abordados por Pistrak com diferentes ênfases ao longo do texto. Portando, nos próximos parágrafos serão apresentados os pontos principais tratados em cada temática, havendo assuntos que transitam entre elas.

Teoria e prática. No momento histórico em que ocorreram as experiências pedagógicas discutidas no livro, acontecia a tentativa de formação de uma cultura socialista na União Soviética e obviamente ela seria pautada na teoria marxista. Neste sentido, Pistrak nega a ideia de neutralidade da educação e critica qualquer adesão a teorias liberais (burguesas) por parte dos professores soviéticos: “(...) sem teoria pedagógica revolucionária, não poderá haver prática revolucionária” (p.19). Referindo-se ao discurso de Lenin na Conferência dos Educadores Políticos em 1920, ele diz que “(...) não podemos atualmente colocar nenhum problema escolar abstraindo as questões de política geral” (p.19). Assim, Pistrak ressalta que o objetivo da sua obra é discutir as questões levantadas a partir das experiências educacionais guiadas pelo marxismo, e não apresentar a teoria (revolucionária) pronta, pois só naquele momento ela começara a surgir.

A escola do trabalho na fase de transição. Pistrak inicia esta seção com a pergunta " o que é a escola do trabalho?" (p.23). Ele questiona como deve ser esta escola dentro do contexto revolucionário que está inserido, afirmando que a escola sempre foi arma nas mãos das classes dirigentes (p.23). Portanto, a nova escola (revolucionária) que estava sendo criada poderia até utilizar formas herdadas da antiga escola (burguesa), mas os seus objetivos deveriam ser novos. O autor cita os princípios que deveriam estar na base da escola do trabalho naquela fase: 1 . Relações com a realidade atual; 2 . Auto-organização dos alunos (p.25).

O primeiro princípio citado por Pistrak está relacionado com a necessidade, naquele período, de se consolidar uma ideologia condizente com a sociedade socialista que se formava. "O objetivo fundamental da escola é, portanto, estudar a realidade atual, penetrá-la, viver nela” (p.26). Deste modo, o estudo dos conteúdos deveria estar pautado no entendimento das questões sociais do período (crítica a sociedade burguesa) e na organização da vida produtiva (conhecimento científico, produção industrial). $\mathrm{O}$ autor menciona, a partir dessa questão sobre ensino, três direcionamentos: 1) a assimilação das noções fundamentais da filosofia marxista; 2) a educação ativa, que permita a assimilação concreta do método científico, o que introduz o trabalho na escola; 3) a formação e a direção das preocupações infantis (p.29).

Pistrak aponta a importância da educação na formação do indivíduo a partir das influências externas. Neste sentido, a educação baseada no método marxista para a interpretação dos fenômenos sociais criaria uma percepção crítica e voltada para a ação. Caberia, então, à escola assumir o controle da formação do intelecto do indivíduo, pois as preocupações assumidas pela criança são alimentadas pelo seu meio social (p.31). Neste ponto, o autor, pautado no materialismo histórico-dialético, nega qualquer naturalidade na formação do sujeito, sendo este resultado de suas experiências. A escola revolucionária 
educaria o sujeito tornando-o munido de conceitos e de uma visão crítica que o possibilitaria ser um construtor da nova sociedade socialista.

Sobre o segundo princípio (auto-organização dos estudantes ou autodireção), Pistrak esclarece que ele não deve ser confundido com as visões das pedagogias burguesas sobre o tema. No sentido revolucionário a autogestão justificasse pela necessidade de construção da nova sociedade, que deveria ser feita de baixo para cima, ou seja, cada sujeito compreenderia seu papel na sua realização. Para a formação desse sujeito atuante na sociedade seria necessário desenvolver: “(...) 1) aptidão para trabalhar coletivamente e para encontrar espaço em um trabalho coletivo; 2) aptidão para analisar cada problema novo como organizador; 3) aptidão para criar as formas eficazes de organização” (p.33). Pistrak destaca a auto-organização como um trabalho sério, que envolve obrigações e responsabilidades. Na seção seguinte do livro, o autor trata diretamente da temática do trabalho na escola.

$O$ trabalho na escola. $\mathrm{O}$ autor sugere que a nova escola deve liquidar a separação entre ensino (conhecimento teórico geral) e educação (formação para a vida social), pois o trabalho é um elemento integrante da relação da escola com a realidade atual (p.41). Pistrak considera que o estudo do trabalho humano deve estar na base dos novos programas escolares e com a participação ativa dos estudantes. Ele apresenta algumas formas de trabalho a serem desenvolvidos na escola de acordo com a faixa etária dos alunos: os trabalhos domésticos, como a participação na manutenção da limpeza e na preparação das refeições; trabalhos sociais, como a limpeza e a conservação de jardins e o plantio de árvores. Pistrak destaca que estes trabalhos coletivos, escolares e extraescolares, contribuiriam para a formação de valores e de um novo modo de vida, onde a escola seria um centro cultural que participa ativamente da vida social (p.47).

Outro elemento apresentado por Pistrak são as oficinas escolares. Elas seriam meios pelos quais, através do trabalho prático, o estudante: compreenderia a essência da divisão do trabalho e a mecanização da produção; desenvolveria uma atitude ativa em relação à produção; desenvolveria os elos que o ligariam futuramente à produção real (p.48). "É assim que a oficina escolar pode oferecer (...) uma introdução completa e suficiente à técnica geral da produção moderna. E esta é que é a finalidade capital da oficina escolar" (p.53). O autor destaca a importância de a oficina produzir objetos de interesse social e que as crianças compreendam a importância deles para a sociedade.

Pistrak trata, também, sobre o trabalho agrícola: "consideramos incontestável que, em nossa época, toda escola deve estar, em maior ou menor medida, em contato com a agricultura" (p.57). Com o objetivo de uma melhor união entre cidade e campo, as escolas urbanas também deveriam participar do trabalho agrícola. Além disso, "a agricultura na escola pode permitir o desenvolvimento da ideia de cooperação, do aperfeiçoamento da exploração agrícola, da intensificação da agricultura, da eletrificação etc." (p.60).

A fábrica é outro ambiente onde, para Pistrak, deve se desenvolver o trabalho escolar. Ela seria entendida no processo educativo como um ambiente que estava, naquele contexto, no centro da atividade produtiva. Entender a fábrica seria, então, um meio de se compreender o sistema produtivo e suas relações sociais e políticas. “(...) Toda a realidade atual desemboca na fábrica. É preciso imaginar a fábrica como o 
centro de uma ampla e sólida teia de aranha, de onde partem inumeráveis fios ligados entre si de maneira a formar os nós múltiplos da vida (...)" (p.64).

Pistrak se refere em seguida aos trabalhos improdutivos, que são aqueles que não produzem valores materiais, como: os administrativos, educacionais, estatais etc. Ele destaca a importância destes trabalhos na construção da nova sociedade, trazendo-os para a formação das crianças no ambiente escolar. Eles seriam realizados pela criança por meio da colaboração na execução de trabalhos internos da escola e poderiam ser ampliados a instituições exteriores a ela. Assim, os trabalhos improdutivos “(...) devem estar integrados na escola enquanto elementos da educação social" (p.69).

A partir das questões que Pistrak pensa sobre a escola, o trabalho e a formação da sociedade soviética, ele apresenta um esboço de um possível sistema escolar. Ele seria dividido em $1^{\circ}$ e $2^{\circ}$ graus, havendo formações específicas para o campo e para as regiões industriais. $\mathrm{O}$ autor salienta a questão do $2^{\circ}$ grau, que "(...) deve compreender uma série de estudos práticos que preparem os alunos para as tarefas administrativas e intelectuais (...)" (p.72). Ele destaca que este nível de ensino, por ser o mais alto da educação básica, não deve ser visto apenas como um preparatório para a universidade. Assim, o $2^{\circ}$ grau deve apresentar uma boa formação geral e um certo grau de preparação profissional.

Pistrak resume o problema educacional da seguinte forma: a escola deve dar uma suficiente formação básica social e técnica; deve ter um caráter prático que facilite a transição entre a escola e a realidade; e deve acostumar o aluno a entender cientificamente o seu trabalho (p.73). Deste modo, desde o $1^{\circ}$ grau o aluno iria se desenvolvendo através do trabalho, isto se intensificaria no $2^{\circ}$ grau de modo que ele

(...) parte das obrigações compreendidas pelo tipo mais simples de trabalho, vai-se adaptando aos hábitos técnicos do trabalho e chega ao trabalho social da escola, no qual participa como membro da coletividade escolar. Finalmente, opera-se a passagem para a prática individual junto às organizações sociais e às instituições públicas externas à escola. (...). (PISTRAK, 2011, p.75)

Pistrak, pensando em uma escola profissional, apresenta explicações detalhadas sobre a preparação para o trabalho no $2^{\circ}$ grau: poucos grupos por categoria profissional; desenvolvimento de três fases na atividade prática (orientação, execução, iniciativa); passagem insensível da vida escolar à vida real (profissional) (p.77). Deste modo, o aluno se desenvolveria ao longo das etapas da formação profissional na escola, o que possibilitaria uma transição quase imperceptível para o mundo do trabalho ao final do ciclo escolar (p.78).

O autor indica a organização científica do trabalho como uma das questões a serem resolvidas na escola. Pistrak esclarece que ela surgiu e se desenvolveu na América e na Europa ocidental com a finalidade de intensificar a produção e aumentar os lucros e a exploração do operário, mas na União Soviética ela deveria ser transformada em meio de libertação (p.79). Partindo deste pressuposto, Pistrak pensa no trabalho sob duas perspectivas: individual e coletiva. No trabalho individual a racionalização estaria relacionada com a melhor utilização do tempo e da força de trabalho na produção. Para o trabalho coletivo, por ser o de grande importância na vida social, Pistrak apresenta meios que estimulem a organização e a autonomia dos estudantes no ambiente escolar, com atividades que envolvam planejamento, execução e balanço dos resultados por parte dos alunos (p.83). 
O objetivo da educação soviética, naquele momento, era a formação da nova sociedade socialista. Neste sentido, Pistrak apresenta três conclusões sobre o trabalho na escola: a natureza da educação, onde o aluno seria educado para a vida social e para a atuação prática na realidade (p.87); o papel cultural da escola do trabalho, que contribuiria na construção de uma cultura socialista com valores diferentes das escolas liberais (p.89); as relações entre ciência e trabalho, buscando-se a união entre teoria e prática com a utilização do conhecimento orientado na utilidade social (p. 93). “(...) Definiremos o trabalho como uma participação ativa na construção social, no interior e fora da escola, e a ciência como uma prática generalizada e sistematizada que orienta completamente essa atividade (...)" (p.93).

O ensino. Sobre esta temática, Pistrak aborda questões sobre os conteúdos, os métodos e a organização da nova escola socialista, enfatizando alguns pontos mencionados anteriormente. Um dos fatores ressaltados pelo autor é a educação social, pautada no marxismo e vinculada à realidade social. Assim, "devemos oferecer na escola apenas conhecimentos científicos que não sejam esquecidos (...), cuja necessidade seja incontestável aos olhos das crianças, conhecimentos que correspondam aos objetivos principais da escola (...)" (p.97). A partir dessa vinculação do ensino com a realidade e os objetivos da escola, as diferentes disciplinas trabalhariam em torno dos principais temas de estudo (p.98).

Pistrak destaca que a função dos programas oficiais de educação é apenas apresentar as diretrizes essenciais para o ensino, cada escola deve adaptá-las de acordo com as suas especificidades (p.102). "O trabalho social da escola será coordenado com todo o trabalho do ensino e o conjunto da vida escolar" (p.103). Deste modo, o programa escolar transforma-se em plano de vida, mas para isso seria necessário: passar do ensino à educação; elaboração de planos de trabalho por todas as instituições escolares; que o programa oficial central estimule a sua realização (p.104).

O método de ensino apresentado por Pistrak é chamado de sistema de complexos, ele foi desenvolvido por Krupskaya, pedagoga soviética e esposa de Lênin. No sistema de complexos são escolhidos temas centrais, que serviriam de ponto de partida para a interpretação da realidade e deveriam ser planejados de maneira interdisciplinar, tendo-se como referência os objetivos do programa escolar. $\mathrm{O}$ objetivo da educação era possibilitar ao aluno uma interpretação da realidade com base no marxismo, "daí deriva a necessidade de organizar as disciplinas do programa em complexos, na medida em que este é o único sistema que garante uma compreensão da realidade atual de acordo com o método dialético (...)" (p.109). É interessante destacarmos que há semelhanças entre o método dos temas geradores de Paulo Freire e o sistema de complexos de Krupskaya. Sobre o método, Pistrak explique que:

(...) o trabalho sobre um dado tema começa da seguinte forma: explicamos às crianças o essencial do próprio complexo, mostrando-lhes por que um dado complexo é importante, como possibilita compreender esse ou aquele aspecto da vida contemporânea, entregando-lhes rapidamente uma visão geral do conjunto do tema, explicando-lhes os temas secundários e as tarefas particulares específicas de cada disciplina no complexo dado. (PISTRAK, 2011, p.122)

Pistrak salienta que o sistema de complexos deve ser usado de maneira que rompa com os complexos (temas) que só fazem os alunos estudarem, passando para os complexos geradores de ação. O sistema seria orientado: pelo trabalho real dos alunos; pela auto-organização dos estudantes (p.126). 
Pensando na questão sobre autonomia e atividade prática, Pistrak analisa o Plano Dalton, método de ensino desenvolvido nos Estados Unidos em 1918 e com influências sobre a União Soviética naquele período. O método é baseado no ensino prático em laboratórios. Pistrak percebe nele alguns pontos positivos, especialmente a autonomia do aluno, mas ressalta que ele gera a desvinculação do aluno com a classe, desestruturando o trabalho coletivo. Devendo ser, então, transformado para que seja utilizado de acordo com os objetivos da educação soviética (p.135-136). O trabalho coletivo envolve a auto-organização dos estudantes, esta é a quinta temática do livro, que será comentada a seguir.

A auto-organização dos estudantes. Pistrak inicia este tema falando como a auto-organização é entendida nas sociedades capitalistas, sendo estimulada de cima para baixo. Nesta visão, o aluno adquire uma autonomia limitada pelas regras da sociedade, vendo a si mesmo como membro de uma democracia imutável, onde ele tem efetivamente pouca atuação nas decisões (p.140-141). Consequentemente, Pistrak pensa na auto-organização de uma maneira nova, pois o objetivo era a participação dos trabalhadores, dos cidadãos, na construção da sociedade socialista soviética.

Os coletivos estudantis (coletivo infantil no texto) são citados pelo autor como instrumentos necessários ao estimulo à auto-organização, eles contribuiriam para despertar preocupações de sentido social, levando as crianças à busca de maneiras para a sua realização. O coletivo infantil surge da “(...) necessidade fundamental de inculcar nas crianças a atividade, a iniciativa coletiva, a responsabilidade correspondente à sua atividade. O coletivo das crianças criará, pelo próprio fato de existir, a autoorganização" (p.146).

Pistrak pensa que para a resolução dos conflitos "a assembleia geral é a expressão mais alta do coletivo infantil, não podendo ser acusada nem de subjetivismo, nem de parcialidade na solução de determinada questão (...)” (p.155). Nela, o educador não desempenharia nenhuma função especial, seria visto como o companheiro mais velho, tendo a sua influência devido apenas a sua autoridade moral (p.155).

A respeito das punições realizadas no ambiente escolar, Pistrak entende que elas são focadas no delito cometido pelo aluno e jamais nas falhas do próprio regime escolar. Ele critica, assim, o fato de a escola estar organizada de modo a valorizar os alunos médios, que correspondem ao padrão, sem considerar as diferenças existentes entre as crianças (p. 157). Para o autor, os alunos que não se adaptam deveriam estimular nos educadores a revisão da organização do regime escolar. No entanto, a questão apresentada por Pistrak, não significa simplesmente atender e concordar com tudo o que as crianças desejem, o que seria destrutivo ao coletivo. Desta forma, caberia ao educador:

em primeiro lugar, levar as crianças a participar na criação de um regime que seja seu, que seja razoável e que corresponda ao sistema geral da educação soviética (...). Em segundo lugar, formar, dirigir e desenvolver as preocupações das crianças, esclarecê-las, partindo de um ponto de vista social determinado (...). (PISTRAK, 2011, p.159)

Para representar a capacidade de organização das crianças, Pistrak menciona a experiência positiva das comunas de trabalho, realizada em Moscou em 1923-1924, quando foram criadas pequenas comunas para abrigar grupos de jovens infratores (p.160). "A experiência das comunas de trabalho é, 
portanto, plenamente conclusiva; e o êxito foi comprovado pela exposição dos objetos nelas produzidos, organizada ativa e quase exclusivamente pelas próprias crianças" (p.161).

Para Pistrak, o trabalho coletivo seria construído gradualmente na escola: cria-se um jornal, mais tarde uma revista, grupos de estudo. "Enfim, nasce a necessidade de uma organização para a formação política e geral" (p.162). Espera-se, deste modo, a construção da participação dos alunos na direção do trabalho da escola. "As crianças devem participar no Conselho Escolar para tomar parte no trabalho orgânico da administração da escola, para intervir em todos os problemas pedagógicos (...)” (p.164).

A auto-organização é pensada por Pistrak como um instrumento de formação capaz de educar os sujeitos pelo trabalho coletivo. Os coletivos estudantis desempenhariam este papel na escola, o autor destaca que eles devem contar com a participação de todos os alunos, havendo eleições para a definição dos cargos e a rotação entre os seus ocupantes. $O$ autor pensa que desta maneira todos teriam a oportunidade de liderar e também atender a decisões de outros quando for necessário (p.168-169).

Pistrak pensa que a natureza das preocupações das crianças provém do meio social (p.174), por isso acredita na possibilidade da educação pelo trabalho coletivo na formação de sujeitos comprometidos com a realidade social. Ele exemplifica este raciocínio, mencionando uma experiência que observou em 1905 na Polônia, quando milhares de crianças participaram de um movimento revolucionário (p.176). Portanto, para Pistrak é fundamental:

(...) a participação independente, coletiva, ativa e criativa da juventude na construção das instituições escolares. Verificamos aqui uma antítese total da escola burguesa, aparentemente democrática, mas, na realidade, profundamente autoritária; e a característica dessa auto-organização, que pode ser definida como a compreensão clara dos objetivos gerais da educação, é também a característica de nosso sistema soviético. (PISTRAK, 2011, p.183)

A obra de Pistrak reflete o espírito revolucionário da União Soviética na década de 1920, quando tentava-se construir as bases e os valores de uma sociedade socialista. Mesmo sendo o relato de experiências historicamente e geograficamente situadas, o livro leva-nos a pensar sobre diferentes possibilidades a respeito da formação humana, visto que tendemos a limitar nossas pretensões de acordo com as concepções e visões de mundo predominantes e "naturalizadas" no nosso tempo. Naquele período, Pistrak criticava a adoção de métodos educativos aparentemente inovadores, mas que serviriam, na prática, para reprodução dos valores individualistas da sociedade capitalista. No contexto social do século XXI, autonomia, trabalho coletivo, capacidade de iniciativa, são exemplos de valores comumente encontrados nos discursos presentes na educação brasileira. Acreditamos, no entanto, na importância de darmos, hoje, a estes conceitos um significado realmente crítico. Assim, os fundamentos apresentados na obra (trabalho coletivo e auto-organização) podem e devem servir-nos de orientação e inspiração para a construção de práticas educativas que almejem contribuir para a formação verdadeiramente crítica e emancipadora dos sujeitos.

Notas 
1 PISTRAK, Moisey M. [1924]. Fundamentos da Escola do Trabalho. Tradução de Daniel Aarão Reis Filho. 3. ed. São Paulo: Expressão Popular, 2011. 192p.

2 Mestrando no curso Mestrado Profissional em Educação Profissional e Tecnológica (PROFEPT) no Instituto Federal de Educação, Ciência e Tecnologia do Triângulo Mineiro. Instituto Federal do Triângulo Mineiro. ORCID: http://orcid.org/00000002-9630-2470 Email: israelrmoreira@yahoo.com.br 